\title{
Ocorrência de Thamnodynastes strigatus (Serpentes, Colubridae) no Escudo das Guianas, estados do Pará e Roraima, Brasil
}

\section{Francisco L. Franco e Talita Gancev Ferreira}

Laboratório de Herpetologia, Instituto Butantan, Av. Vital Brazil, 1500, 05503-900, São Paulo, SP, Brasil. E-mail: flfranco@butantan.gov.br.

Keywords: Serpentes, Colubridae, Thamnodynastes strigatus, geographic distribution, Amazonia, Guiana Shield, Brazil.

Palavras-chave: Serpentes, Colubridae, Thamnodynastes strigatus, distribuição geográfica, Amazônia, Escudo das Guianas, Brasil.

O gênero Thamnodynastes Wagler, 1830 é composto por treze espécies (Franco e Ferreira 2003, Franco et al. 2003) distribuídas por grande parte da América do Sul, desde aproximadamente $10^{\circ} \mathrm{N}$, na Colômbia (Perez-Santos e Moreno 1989), até $37^{\circ} \mathrm{S}$, na Argentina (Bellagamba e Vega 1996). Thamnodynastes strigatus (Günther, 1858) atinge o maior porte entre as espécies do gênero. Pode ser facilmente diagnosticada pela posse de 19 fileiras de escamas dorsais lisas no meio do corpo e manchas escuras nas bordas anteriores das infralabiais que afilam em direção às mentonianas ou gulares, formando pontas, à semelhança de dentes (Franco e Ferreira 2003).

Thamnodynastes strigatus é registrada para o sul e sudeste brasileiro, Argentina, Uruguai e Paraguai (Hoge 1953, Peters e Orejas-Miranda

Recebido em 15 de maio de 2003.

Aceito em 5 de agosto de 2003.

Distribuído em 19 de dezembro 2003.
1970, Lema e Fabián-Beurmann 1977, Cei 1993, Achaval 1997, Franco e Ferreira 2003). No Brasil, essa espécie é conhecida para as regiões serranas do estado do Espírito Santo em direção ao sul, ocorrendo nos estados do Rio de Janeiro, Minas Gerais, São Paulo, Paraná, Santa Catarina e Rio Grande do Sul, onde também pode ser encontrada em áreas baixas (Hoge 1953, Franco e Ferreira 2003). Todas as localidades brasileiras em que a espécie já foi registrada pertencem ao Domínio Tropical Atlântico e das Coxilhas (Ab'Saber 1977).

Na Coleção Herpetológica do Museu Nacional, Rio de Janeiro, foram localizados dois exemplares de T. strigatus procedentes do Escudo das Guianas, estados do Pará e Roraima, no norte do Brasil.

O exemplar MNRJ 8735, composto apenas pela cabeça e parte do pescoço, é procedente de Tapiru, rio Paru, município de Almeirim (PA). Esse rio nasce no cume da Serra do Tumucumaque $\left(02^{\circ} 25^{\prime} \mathrm{N}, 55^{\circ} 31^{\prime} \mathrm{W}, 400 \mathrm{~m}\right)$, na divisa entre o Brasil e Suriname, e deságua no 
rio Amazonas $\left(01^{\circ} 33^{\prime} \mathrm{S}, 5^{\circ} 37^{\prime} \mathrm{W}, 60 \mathrm{~m}\right)$. A vegetação é composta predominantemente por floresta de terra firme, havendo áreas abertas de cerrado proximo à cabeceira do rio Paru (Hoogmoed 1979).

O exemplar MNRJ 0668, um macho adulto, é procedente do Alto Catrimani, provavelmente do município de Iracema ou Mucajaí. O rio Catrimani nasce no município de Iracema, ao sul da Serra Parima (02²5'N, 6320'W, 1000 $\mathrm{m})$, corre por Mucajaí e deságua no rio Branco $\left(00^{\circ} 27^{\prime} \mathrm{N}, 61^{\circ} 44^{\prime} \mathrm{W}, 100 \mathrm{~m}\right)$, município de Caracaraí. Vanzolini e Carvalho (1991) descreveram a área como um platô muito acidentado, repleto de cachoeiras. A vegetação é de floresta de terra firme.

O exemplar MNRJ 0668 apresenta as seguintes características: comprimento rostro cloacal de $473 \mathrm{~mm}$, comprimento da cauda de $135 \mathrm{~mm}$ e comprimento da cabeça de $24,5 \mathrm{~mm}$. Escudo nasal único. Uma pré-ocular e duas pósoculares. Duas temporais anteriores, duas temporais posteriores no lado direito e três no lado esquerdo. Supralabiais $8 / 8$, quarta e quinta tocam o olho. Infralabiais $9 / 9$, primeira a quinta contatam as mentonianas. Escamas dorsais lisas em 19/19/15 fileiras. Escamas ventrais 146. Escamas subcaudais em 60 pares. A coloração e os desenhos do exemplar em álcool $70 \%$ são considerados normais para a espécie. Exemplar castanho escuro, dorso com padrão variegado, com região lateral escurecida. Lateralmente, a cabeça mostra labiais superiores e inferiores com manchas escuras em suas bordas. Faixa pós-ocular escura em direção à comissura labial. Região ventral da cabeça clara, destacandose as manchas escuras nas infralabiais e gulares, além de uma linha quase negra seguindo o sulco mentoniano. Ventre um pouco mais claro que o dorso, principalmente no terço anterior, com um par de linhas laterais muito nítidas e regulares. Há um segundo par de linhas menos conspícuas, centrais a esse par lateral, que às vezes se fundem em uma única linha, principalmente no terço posterior. $\mathrm{O}$ ventre da cauda apresenta apenas o par lateral nítido.
Para o exemplar MNRJ 8735, são apresentadas apenas as características que representam variações em relação ao espécime anterior. Comprimento da cabeça de 22,6 mm. Escudo nasal semi-dividido. Três temporais posteriores de ambos os lados. Escamas dorsais lisas em 19 fileiras no início do corpo. A coloração do exemplar em álcool segue a descrição do exemplar anterior, no que foi possível observar. A coloração de fundo é levemente mais clara, aumentando o contraste claro-escuro. Ressalta-se que o capuz cefálico escuro apresenta uma projeção lateral em direção à articulação quadradomandibular, quase tocando a faixa pós-ocular.

Este encontro amplia em cerca de $2500 \mathrm{~km}$ a distribuição de Thamnodynastes strigatus, evidenciando a existência de pelo menos mais uma população disjunta da população do sul e sudeste da América do Sul (Franco e Ferreira 2003). Hoogmoed (1983) citou a ocorrência de duas espécies de Thamnodynastes na região das Guianas, uma corretamente identificada como $T$. pallidus (Franco e Ferreira 2003) e outra que, de acordo com a chave de Peters e OrejasMiranda (1970), era identificada como $T$. strigatus. Porém, devido a diferenças morfológicas entre os espécimes das Guianas e os de T. strigatus, Hoogmoed (1983) identificou seus exemplares, tentativamente, como $T$. strigilis, ressaltando que poderiam pertencer a uma espécie ainda não descrita.

\section{Agradecimentos}

Agradecemos Ronaldo Fernandes e Marcelo Soares (Museu Nacional, UFRJ) pelo empréstimo do material e informações sobre os exemplares, Ronaldo Fernandes e Daniel Silva Fernandes pelas sugestões e leitura do manuscrito, Marinus Hoogmoed e um revisor anônimo pelas valiosas contribuições e sugestões, os funcionários e estagiários do Instituto Butantan, em nome de Valdir J. Germano, pelo auxílio em diversas etapas deste trabalho, e à FAPESP pelo subsídio financeiro.

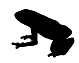




\section{Referências Bibliográficas}

Ab'Saber, N. A. 1977. Os domínios morfoclimáticos na América do Sul. Primeira aproximação. Geomorfologia 52: 1-21.

Achaval, F. 1997. Actualización sistemática y sinonímica de los reptiles del Uruguai com comentários e distribucion. Tese de Doutorado Não-Publicada. Universidad de la República, Faculdad de Ciências, Montevideo, Uruguai.

Bellagamba, P. J. e L. E. Vega. 1996. Geographic Distribution. Thamnodynastes hypoconia. Argentina: Buenos Aires. Herpetological Review 27: 36.

Cei, J. M. 1993. Reptiles del Noroeste y Este de la Argentina. Herpetofauna de las Selvas Subtropicales, Puna y Pampas. Torino, Museo Regionale di Scienze Naturali (Monografie 14). 949 pp.

Franco, F. L. e T. G. Ferreira. 2003. Descrição de uma nova espécie de Thamnodynastes Wagler, 1830 (Serpentes, Colubridae) do nordeste brasileiro, com comentários sobre o gênero. Phyllomedusa 1: 57-74 (2002).

Franco, F. L., T. G. Ferreira, O. A. V. Marques e I. Sazima. 2003. A new species of a hood-displaying Thamnodynastes (Serpentes: Colubridae) from the Atlantic forest in southeast Brazil. Zootaxa 334: 1-7.

Hoge, A. R. 1953. Notas herpetológicas. Revalidação de
Thamnodynastes strigatus (Gunther, 1858). Memórias do Instituto Butantan 24: 157-172 (1952).

Hoogmoed, M. S. 1979. The herpetofauna of the Guianan region. Pp. 241-279 in W. E. Duellman (ed.), The South American Herpetofauna - its origin, evolution and dispersal. Lawrence, Museum of Natural History, The University of Kansas. (Monograph n. 7).

Hoogmoed, M. S. 1983. Snakes of the Guianan region. Memórias do Instituto Butantan 46: 219-254 (1982).

Lema, T. e M. E. Fabián-Beurmann. 1977. Levantamento preliminar dos répteis da região da fronteira BrasilUruguai. Iheringia, série Zoologia 50: 61-92.

Pérez-Santos, C. e A. G. Moreno. 1989. Una nueva especie de Thamnodynastes (Serpentes: Colubridae) en el norte de Colombia. Bolletino del Museo Regionale di Scienze Naturali, Torino, 7: 1-9.

Peters, J. A. e B. Orejas-Miranda. 1970. Catalogue of the Neotropical Squamata. Part I. Snakes. Bulletin of the United States National Museum 297: 1-347.

Vanzolini, P. E. e C. M. Carvalho. 1991. Two sibling and sympatric species of Gymnophthalmus in Roraima, Brasil (Sauria, Teiidae). Papéis Avulsos de Zoologia, São Paulo 37: 173-226. 